\title{
ESPAI OBERT. MULTIDISCIPLINARY COOPERATIVE LEARNING EXPERIENCE
}

\author{
Yolanda Hernandez Navarro, Pasquale Dato, Chele Esteve Sendra, María \\ Felicia Puerta Gómez
}

Universitat Politécnica de Valéncia (SPAIN)

\begin{abstract}
ESPAI OBERT is a pilot experiment to improve team-based collaborative learning that aims to promote transversal knowledge through developing skills and attitudes for effective performance of functions in work environments. To achieve this objective, the participants of the simulated work experience are organized into work teams and must respond to a challenge in the form of an open and contextualized problem, which requires learning and a functional use of knowledge.
\end{abstract}

The challenge is to propose an artistic space in an uncultivated field of the Valencian Orchard (This project is part of the framework of the Cooperation and Development Project [P]Horta Oberta. Meeting place of participation for sustainable alternatives, selected by the Programme of activities of solidarity and social participation (GLOCAL 2020) of the Universitat Politècnica de València. Specifically, the activity is motivated by the participation of the proposals in the ideas competition Espai Obert. Sustainable ephemeral spaces, which aims to encourage creativity in the context of the ephemeral from an artistic perspective.

The six-week experience is tested on a small group of students coming from the Higher Technical School of Architecture and the Faculty of Fine Arts. These students are either enrolled in the subject of Architectural Composition, 4th Degree in Fundamentals of Architecture or Project Methodology, 3rd Degree Fine Arts. The participating collective are structured into multidisciplinary teams.

The methodology used for this experiment is Direct Instruction, a common practice based on two learning approaches: Experiential Learning and Inquiry Learning and the Project-Based Learning Method. Techniques such as the Whirlwind of Ideas will be used in the initial phase, while Structured Debate will be used in the final phase. Cooperative learning will be tested throughout the process using techniques such as Spontaneous Mentoring.

In consideration of this six-week experience, the results, which are expected to motivate the repetition of the action and/or its improvement, are: 1. An improvement of teamwork skills, 2. Easy acquisition of flexible and contextualized knowledge, 3. Promotion of critical thinking and self-regulation skills, 4. Encouragement of positive interdependence between students and 5. An improvement of motivation to learn.

Keywords: Multidisciplinary learning, cooperative learning, architecture, fine arts, ephemeral installation, Valencian orchard.

\section{INTRODUCTION}

\subsection{Teamwork is more than working together}

Group work can be an effective method to motivate students, encourage active learning, and develop key critical-thinking, communication, and decision-making skills. We must not forget that architectural design is a complex process that involves different roles It is necessary to promote real situations that bring us closer to real situations in the formative stage. Group working can make study more efficient and pleasurable. Working with others enables you to pool your ideas and see problems from different perspectives. Students need to be immersed in learning environments that promote real learning in real contexts. The simulation in real scenario, where students' active collaboration with other students from different backgrounds team up to provide solutions to everyday problems, is more attractive. The lack of active collaboration between different participants from the early stages of design process onwards is also seen later in practice. The current labor market demands much more than the sum of individualities. But in most cases, the result of the experience turns negative. The various causes lie in the student body, in the teaching staff and in the institution [1]. 
Students face a shortage of interdisciplinary knowledge and the achievement of communication skills from working on different projects in cooperation with other disciplines. Students shy away from this practice more and more and when faced with a possible choice. Pupils prefer to be confident to their own autonomous work, from their individuality. There are several important reasons for this decision: individualism and competitiveness. This leads to unproductive confrontations and discussions, poor communication that generates an internal lack of coordination and repeated work, and the lack of rules for coexistence that have an impact on the unproductiveness of the meetings.

Teachers, among other reasons, show a lack of information and training, disinterest, inertia, comfort, fear, loss of prominence, and lack of time and motivation [2], which makes them reluctant to change and improve their teaching-learning method.

Institutions, for their part, are neither prepared nor pursuing working towards types of learning other than direct instruction. Hence, there continue to be inadequate infrastructures, insufficient class time, and a great imbalance between teaching and research in the curriculum, among others [2].

With this background, the usual practice does not make it difficult to work in a group while working in a team. Teachers may consider, wrongly, that their students have acquired skills and competencies needed to work in a team, and that it is therefore sufficient to say "this work must be done on a computer" to actually get good results.

Although the success of teamwork experiences requires the commitment of 3 parties the actions of the teaching staff can have a great positive influence on the other two. Therefore, the teacher's work in the classroom is essential; it is not enough to group them together and tell them to work together, it is necessary to teach them.

Some of the habits that teachers can inspire in students are: making personal presentations among the members of each team to generate empathy, rotating roles among the participants, having clear responsibilities with the team (individual enforceability), constantly remembering the common objective to avoid deviations and waste of time, assigning parts of work according to each one's personal strengths, agreeing on communication rules to make coordination and meetings more effective, structuring time (individual self-employment and team meetings), and detecting conflicts and redirecting them into mutual respect. In summary, the teacher must observe, care for and encourage interaction between students, something that is commonly ignored, because it is a factor that influences how they learn, their sense of community, and their self-esteem [2] [3].

Authentic teamwork leads to positive interdependence: success in each student's results depends on the results of the other classmates. Therefore, it is necessary to collectively visualize the goal as unique and identical for all to speak of cooperative learning [1] [2].

A synthetic-comparative table between group and team work is presented below.

Table 1. Comparison between the models of group work and teamwork. Excerpted from [2]

\begin{tabular}{|c|c|c|}
\hline ELEMENT & GROUP & TEAM WORK \\
\hline Interest & Result of the work & Maximum performance of all \\
\hline Responsibility & Group only & Individual \\
\hline Groups & Homogeneous & Heterogeneous \\
\hline Leadership & Unique and personal & Shared \\
\hline Help & Freedom to decide whether to help and to whom & Responsibility to help other members \\
\hline Goal & Complete the task & Maximum possible learning \\
\hline Social skills & They are supposed & taught (and learned) \\
\hline Role of the teacher & Mere evaluator of the final result & Auditor and supervisor of the workplace \\
\hline Workplace & Outside the classroom & In the classroom \\
\hline
\end{tabular}




\subsection{Multidisciplinary work}

The teams that achieve the best results are formed by different training profiles. Compared to unidisciplinary work, interdisciplinary competence induces the analysis, comparison, and contrast of perspectives from different disciplines, thus developing intellectual maturation. Specifically, the interdisciplinary approach activates metacognitive skills, critical thinking, and personal epistemology [4].

Metacognitive skills allow everyone to know their own cognitive functioning as well as work on selfcontrol and regulation of cognitive processes. Meanwhile, critical thinking questions the habitual way of thinking and acting, and prepares one to think differently. "If a person is adept at thinking critically, he is adept at gathering, analyzing, synthesizing, and assessing information, as well as identifying misinfonnation, disinformation, prejudice, and one-sided monological argumentation" [5]. Epistemological development, development affects the level of participation of students in the learning process [6] and reading comprehension [7], among others, and conflicts the student's personal epistemological beliefs with the complex information found during the development of university studies [8].

The university subjects' development on many occasions, occurs in isolation and without coordination, despite the strong relation between parts in many cases in isolation and without coordination with the topics, even being strongly related in many cases. This obstacle must be reversed which can be done with the help of the teachers. Starting from an interdisciplinary approach, the teacher interacts with his peers from other subjects to coordinate and plan learning objectives, content and results, taking a common challenge as reference.

\subsection{Contextualization of the experience and objectives}

To a particular university context characterized by large group work, in turn limited in its development to a single disciplinary field, various professors, from the Faculty of Fine Arts (FBBAA) and the Higher Technical School of Architecture (ETSA) of the Universitat Politècnica de Valencia (UPV), with common interests in the protection and conservation of the Valencian Huerta, have designed and planned a Cooperation and Development Project "(P)Horta Oberta. Participation place for sustainable alternatives", selected to form part of the GLOCAL 2020 Program, support for UPV solidarity and social participation activities.

Although the $(P)$ Horta Oberta project presents several phases with different objectives, we focus on the initial "ESPAI OBERT. Espacios efímeros sostenibles" closely related to the content of this article. It is an ideas competition that is intended to boost creativity in the field of the ephemeral from an artistic perspective. To do this, the challenge is to propose a space on an uncultivated plot in the Valencian Huerta, capable of temporarily hosting a place for reflection and social gathering around issues related to the sustainable development of the territory. This competition phase is complemented by other phases, here only stated: participation in the workshop for the construction of the winning proposal, use of the installation and, finally, the dismantlement ${ }^{1}$.

With the aim of developing a cooperative and interdisciplinary work, teachers from the ETSA and FBBAA direct the specific learning of their subjects (implementation of sessions, design of materials and activities), to the common challenge that motivates participation in the contest. For this, $30 \%$ of the students enrolled in the subject of Architectural Composition, 4th Grade in Fundamentals of Architecture (ETSA) and \% of students in Project Methodology, 3rd Grade Fine Arts (FBBAA) are involved. The group involved, on the proposal of the teaching staff, has organized into interdisciplinary teams of between 6 and 8 members, with architectural and fine arts training, to work for 6 weeks on this challenge in the form of an open and contextualized problem, which requires learning and functional use of knowledge.

\footnotetext{
${ }^{1}$ More information can be found through the project website http://hortaoberta.gestionsostenible.com/.
} 


\section{METHODOLOGY}

\subsection{Planning and method}

In schedule of two weekly sessions of both subjects involved direct instruction has been reduced [9] [10] to one of the weekly sessions, implementing in the remaining 90 'session a common practice with a double focus.

On the one hand, experiential and inquiry learning [11] developed in stages: first, an individual and collaborative investigation about the current problems regarding the conservation of the Valencian Garden, compositional and project methods and materiality; second, a communication and discussion of conclusions based on evidence and; third, learning to learn [12]

On the other hand, cooperative learning focused on peer help and positive interdependence that ensures the solidarity relationship between team members. Students learn more and better when they help each other [13] and this relationship has a mutual benefit because those with fewer skills feel calmer and better integrate the knowledge explained by their peers, while those with more Competency level become aware of what they know or need to review through language, thus generating reflective knowledge [14].

The methodology used has been the project-based learning method (ABP), through team participation in the ESPAI OBERT contest.

The intellectual challenge of designing an artistic space that must meet a series of requirements is posed: functional, with the capacity to host a moderately large group of people (over 30) for the purpose of meetings, round tables, talks and exhibitions; constructive, with the use of recycled materials and without impact on the place at the time of its dismantling; compositional, with the approach of innovative design solutions; economic, through simple proposals from the budgetary point of view. In this way, the challenge is defined and to respond to it, the application and functional use of knowledge previously acquired in the direct instruction process is required, as well as autonomous research by each team.

\subsection{Functions of teachers and students}

Once the challenge is established, the tasks and responsibilities of teachers and students are defined. Firstly, in relation to the teaching staff, the four teachers involved in the project prepare the learning environment in a large FBBAA classroom equipped with tables and chairs organized in groups of 8 positions, as well as ensuring the sufficient supply of plugs for electronic devices, classroom computer and projector. Secondly, the teachers write a decalogue with the attitude that the teaching team must show both the actions that they must take and those that they must avoid. We emphasize the attitude of the teacher who must be motivating, guiding, and mediating, staying in the background. The teacher must be flexible when faced with the critical thinking of the students and promote selfevaluation to guide them in finding the best solution to the problem [15]. They must also facilitate times inside and outside the classroom to meet the needs of the students. For their part, students receive information about the work system and its role, influencing awareness of their active role in the process, in which the team's learning rhythm is autonomous and the results will depend on the degree of implication of its members and that they must practice the investigation, the construction of knowledge and the decision making [16], all following an adequate temporal planning.

\subsection{Phases}

The 6 sessions scheduled for teamwork are structured in 3 phases:

The first takes place during the initial two sessions and includes a visit to the work area, so that the student gets in touch with the real context. A tour is made between cultivation fields in different states of tillage and instructions are given by the teachers to arouse the curiosity of the students, in aspects such as materials of daily use in agricultural work, the shapes, geometry and color that are used. can identify in the different characteristic elements of the place. This visit, initially directed by the teaching staff (30 '), later becomes free-moving and self-taught, with the aim of initiating the student in the autonomous work of investigation and deepening of knowledge from two different disciplines, architecture and fine arts. The teachers are present in the area but only carry out guide work on where to find answers to the questions asked. 


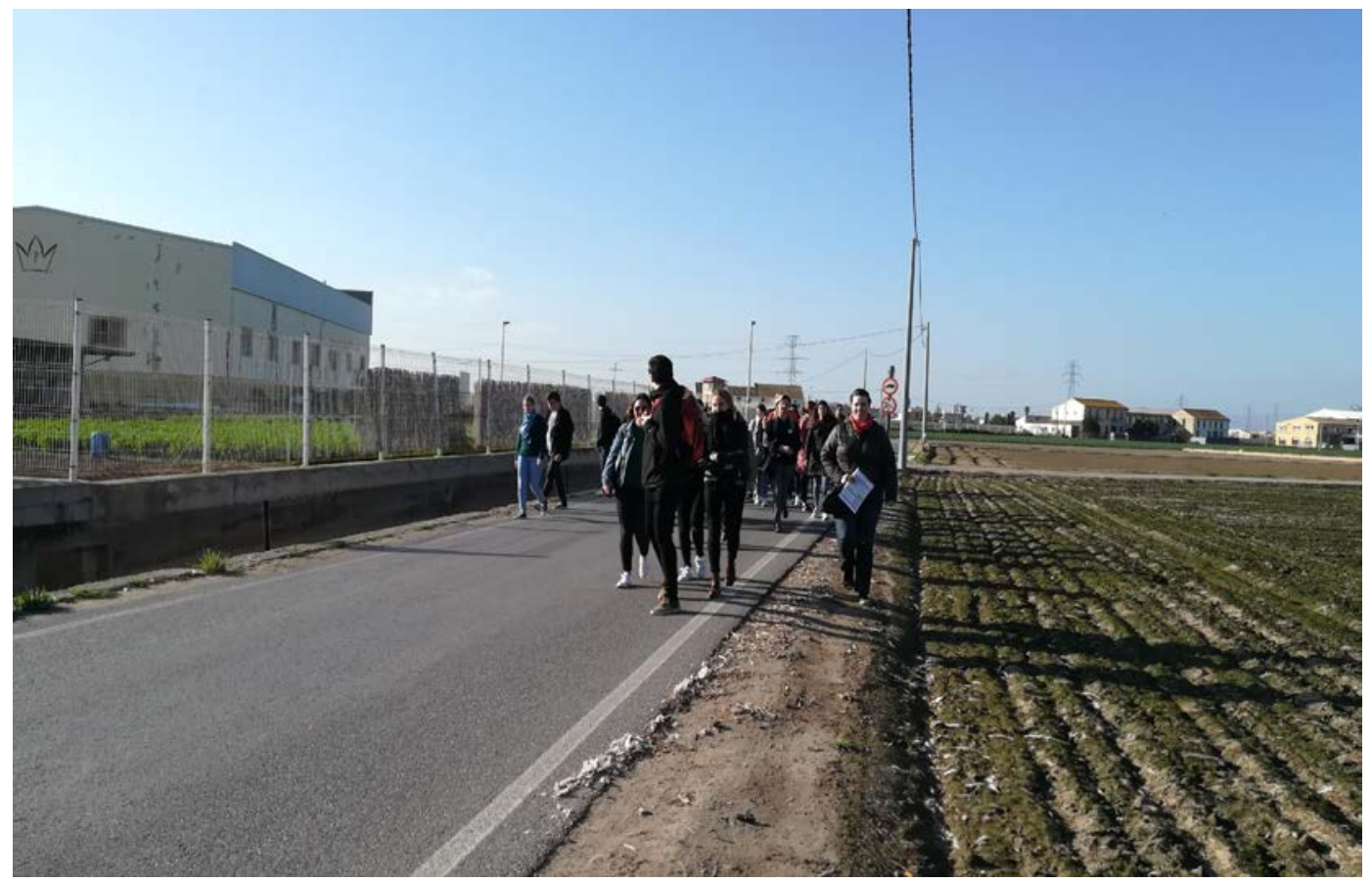

Figure 1. Visit to the Valencian Huerta environment. Photograph of the authors.

The second session is intended to share the observations in the area visited, as well as questions and curiosities discovered by the students. From this and at different rhythms in each team the whirlwind of ideas spontaneously arises. With the initial problem well defined, and equipped with pencil, paper and electronic devices, they begin to write down and outline concepts and forms that they consider interesting and should be reflected in the project solution. In this way, individual free expression is promoted as a communication tool. The work of the teaching staff in this period is to guide the discussion towards an orderly system in which, after the expression of the ideas of each person, a round of opinions begins that highlights the strengths and opportunities as well as the threats. In this way, it is intended to screen ideas that help decision-making. In this sense, it is also encouraged to appoint a member as secretary of the team to prepare the minutes of the meeting that will then be available to all members.

The second phase takes place during the three central sessions of the experience and is dedicated to developing the idea agreed upon in the previous phase. For this, guided by the teachers, a first activity is coordinated in which each member highlights their most notable qualities and possibilities of contribution to work in order to get the best out of each one. This allows to know each member of the team on a personal level and thus support a distribution of roles. Having arrived here, the process of socialization among the team members has already begun unconsciously, which has generated, both the sense of belonging as well as the first disagreements. Again, the role of the teacher is very important here, because in anticipation of this situation he has prepared and has provided the students with some rules of coexistence. In the rules, it is established how to assign roles (leader / mediator, secretary, experts, timekeeper, and devil's advocate) to the members based on their strengths, with differentiated responsibilities, which in turn make them aware of their necessary participation in the process. This phase intensifies the feeling of solidarity experienced in the exchange of information, the co-construction of knowledge, and peer tutoring. After the teaching facilitated by the teacher in the direct instruction classes, the students help each other, which shows the positive interdependence. Recipient students are very open to the help of peers while the assistants give feedback by testing their expressive abilities and identifying their limitations. 


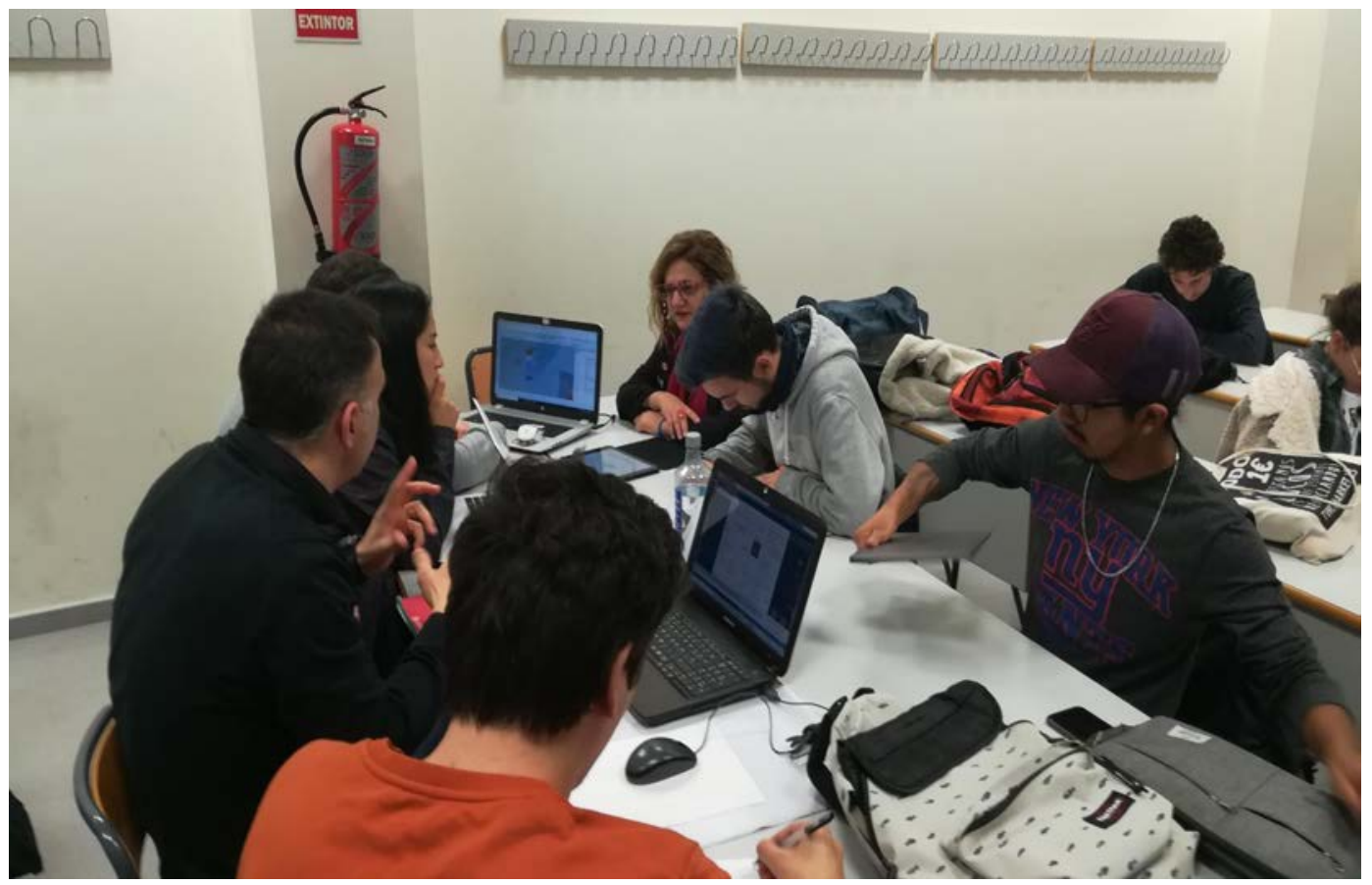

Figure 2. Team working and interacting with one of the teachers. Photograph of the authors.

The last phase takes place in the last session and is dedicated to the structured final debate, in which each team leader presents the final solution proposed by their team. To do this, each team has previously worked on the ability to synthesize the process in a short 10-minute presentation, after which a round of opinions is opened, which serves as a peer evaluation. The secretary of each team points out the weaknesses and strengths of the solution in full view of his teammates and together they are considering possible ways to improve the final solution. This practice, in addition to being a very fruitful form of evaluation, favors the ability to argue and improve oral expression, tolerance and plurality of ideas, as well as develops critical thinking. To end the ESPAI OBERT project, a survey evaluating the experience has been disseminated among the project participants.

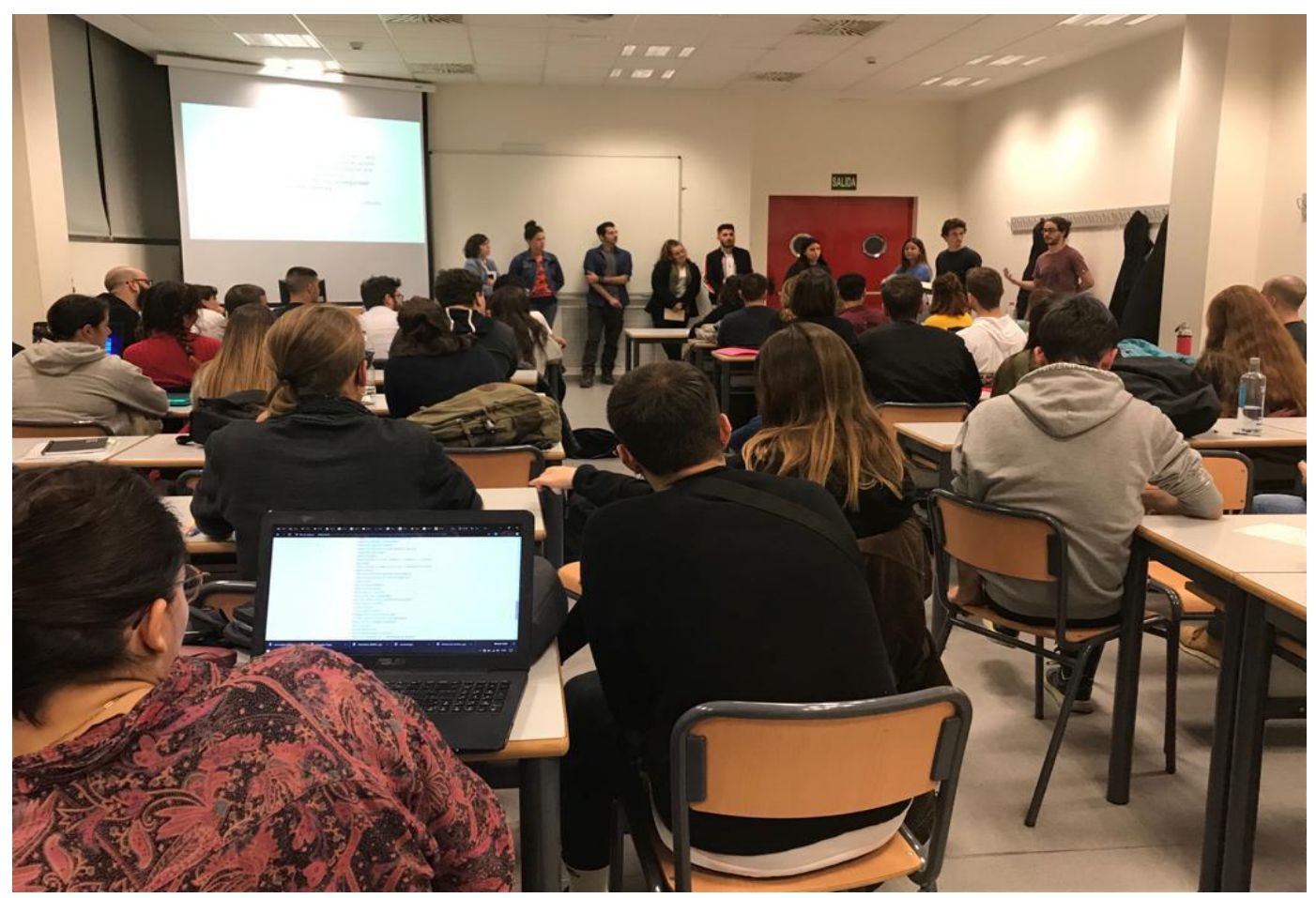

Figure 3. Final debate. Photograph of the authors. 


\section{RESULTS AND CONCLUSIONS}

Following the evaluation of the results obtained, the opinion survey of students and comparing results with previous years that has not used the ABP is demonstrated: Working in groups is a common practice in the two disciplines involved, Architecture and Fine Arts.

- $93 \%$ of respondents agree that it is appropriate to link academic work with professional life, rehearsing real teamwork environments that facilitate the acquisition of flexible and contextualized knowledge [17].

- $60 \%$ have positively valued the relationship of the project with the learning objectives of the subjects involved and the role of the teacher in this process. This indicates a slight improvement in the learning to learn competence in which the planning of the project is linked to the curricular contents and the reflection tutored by the teaching staff [18] [19]

- The relationship between students of the same course has improved. $80 \%$ have felt integrated in their team in particular and in the group in general and more than $70 \%$ have considered interdisciplinary work beneficial, recognizing a diversity of approaches that has enriched personal tolerance, as well as other social competencies.

- Collaborative work has fostered debate among peers, has answered individual questions and has discovered aspects unknown to the rest of the members, thus confirming the promotion of critical thinking and self-regulatory skills [20] [12].

- The planning of teamwork in the classroom and during school hours has been positive and well received. It is evident that $75 \%$ of the participants had no need to meet outside of class time. This is an indicator for the improvement in the planning of the following course, since the class time is presented as an opportunity for the interaction and coordination of the teams, making this task very difficult outside these hours, due to the different training and work casuistry presented by the students.

- The perception of the time allocated to carrying out the work has improved compared to previous years, due to the temporary planning of the process, the adoption of roles and the distribution of responsibilities, as well as the role of the teaching staff as guide-counselor and reviewer of the process.

- The distribution of roles has stimulated positive interdependence [15].

- The grades of the works developed with ABP have improved considerably compared to the same type of group work without ABP of previous years. Therefore, the modification introduced in the curriculum can be considered an improvement. However, the students warn of the difficulty of processing textual sources and relating them to the specific learning objective as well as difficulty in extracting and articulating essential information, leading to chaos and stress. Therefore, if possible, the role of the guide-counselor teacher should be reinforced.

In conclusion, ESPAI OBERT, as a cooperative work experience, has improved the competence of teamwork by influencing personal disposition and collaboration between individuals towards common goals, assuming responsibilities, and contributing to collective development. This is positive interdependence, and the success of the process is based on the dimensions: identity and feeling of belonging to a group, communication and interaction between members, execution and implementation of actions according to a pre-established plan and regulation of conflicts [21].

ESPAI OBERT as an interdisciplinary experience has enriched the analysis, comparison and contrast of perspectives from the disciplines of Architecture and Fine Arts, thus promoting intellectual maturation.

ESPAI OBERT as an ideas competition linked to the extra-academic environment has motivated the participatory attitude of the students, resulting in a conscious acquisition of competencies and skills such as autonomous research and study, teamwork, time planning and the ability to express oneself adequately, all of which are highly demanded skills in the current work environment.

\section{REFERENCES}

[1] R. García, JA Traver, R. García, JA Traver, and I. Candela, 'Cooperative learning Fundamentals, characteristics and techniques', 2019. 
[2] VJ Traver and JA Traver, 'Why don't we teach to learn cooperatively?', $X$ Conference on Univ. Computer Science, pp. 297-304, 2004.

[3] R. Satorre, J. Miró Julià, F. Llorens Largo, and P. Palmer, 'Twelve Proposals and a Reflection', ReVision, vol. 6, no. 1 p. 4, 2013.

[4] L. Ivanitskaya, D. Clark, G. Montgomery, and R. Primeau, 'Interdisciplinary learning: Process and outcomes', Innov. High. Educ., Vol. 27, no. 2, pp. 95-111, 2002, doi: 10.1023 / A: 1021105309984.

[5] D. Costa, M. Elena, VL S, and E. Price, 'Metacognition and Higher Order Thinking: An Interdisciplinary Approach to Critical Thinking the Humanities', 1986.

[6] SS Wineburg,' On the Reading of Historical Texts', Am. Educ. Res. J., vol. 28, no. 3, pp. 495-519, 1991.

[7] MP Ryan, 'Monitoring text comprehension: Individual differences in epistemological standards', J. Educ. Psychol., vol. 76, no. 2, pp. 248-258, 1984, doi: 10.1037 / 0022-0663.76.2.248.

[8] J. Perry, WG, 'RESUME in Thought and Values of tudents in a Liberal Arts College A Validation of a Scheme', 1968.

[9] BV Rosenshine, 'Content, Time and Direct Instruction', in Research on Teaching : Concepts, Findings, and Implications, P. Peterson \& HJ Walberg, Ed. California: McCutchan Publishing Corporation, 1979.

[10] RE Kirschner, PA, Sweller, J. \& Clark, 'Why Minimal Guidance During Instruction Does Not Work: An Analysis of the Failure of Constructivist, Discovery, Problem-Based, Experiential, and InquiryBased Teaching ', Educ. Psychol., vol. 41, no. 2, pp. 75-86, 2006, doi: 10.1207 / s15326985ep4102.

[11] S. Papert, Mindstorms: children, computers, and powerful ideas. London: Basic Book, Inc., 1980.

[12] CA Hmelo-Silver, CE; Duncan, RG and Chinn, 'Scaffolding and Achievement in Problem-Based and Inquiry Learning: A Response to Kirschner, Sweller, and Clark (2006)', Educ. Psychol., vol. 42, no. 2, pp. 99-107, 2007, doi: https://doi.org/10.1080/00461520701263368.

[13] M. Montanero Fernández, 'Pedagogic methods for a new century. Are they really innovative? ', Teor. the Educ., vol. 31, no. 1, pp. 5-34, 2019, doi: 10.14201 / teri.19758.

[14] MTH Roscoe, RD and Chi, 'Understanding Tutor Learning: Knowledge-Building and KnowledgeTelling in Peer Tutors' Explanations and Questions', Rev. Educ. Res., Vol. 77, no. 4, pp. 534-574, 2007.

[15] J. Reverte Bernabeu, AJ Gallego Sánchez, R. Molina-Carmona, and R. Satorre Cuerda, 'Jenui 2007', 2007.

[16] J. Sánchez, 'What the studies say about Project Based Learning ', Current. Pedagogical, vol. 1 p. 4, 2013.

[17] K. Chu, SKW, Tse, S, K. and Chow, 'Using collaborative teaching and inquiry project-based learning to help primary school students develop information literacy and information skills', Libr. Inf. Sci. Res., Vol. 33, no. 2, pp. 132-143, 2011, doi: https://doi.org/10.1016/j.lisr.2010.07.017.

[18] A. Fuertes Case, J. García Sánchez, O. Arias Gundín, R. Fidalgo Redondo, and M. Fernández Martínez, 'Problem-based learning: review of international empirical studies', Rev. Educ., No. 341, pp. 397-418, 2006.

[19] JC Patall, EA, Cooper, $H$. and Robinson, 'The effects of choice on intrinsic motivation and related outcomes: A meta-analysis of research findings.', Psychol. Bull., vol. 134, no. 2, pp. 270-300, 2008, doi: https://doi.org/10.1037/0033-2909.134.2.270.

[20] D. Dochy, F., Segers, M., Van den Bossche, P. and Gijbels, 'Effects of problem-based learning: a meta-analysis', Learn. Instr., vol. 13, no. 5, pp. 533-568, 2003, doi: https://doi.org/10.1016/S09594752(02)00025-7.

[21] C. Torrelles Nadal, J. Coiduras Rodríguez, S. Isus Barado, F. Carrera Farran, G. París Mañas, and J. Cela Ranilla, 'Teamwork competence: definition and categorization', Profr. Rev. Curric. and Form. from Profr., vol. 3) No. December, 2012. 